\title{
Method for Pedestrian Crossing Risk Assessment and Safety Level Determination: the Case Study of Tallinn
}

\author{
Maria Pashkevich \\ Tallinn University of Technology, Ehitajate tee 5, 19086 Tallinn, Estonia
}

Anna Krasilnikova

Belarusian National Technical University, Nezavisimosti Ave. 65, 220013, Minsk, Belarus

\section{Dago Antov}

Tallinn University of Technology, Ehitajate tee 5, 19086 Tallinn, Estonia

\section{SUMMARY}

Pedestrians are a part of vulnerable road users which safety requires a special attention. Official statistics in Estonia from the last decade returns the following numbers: around 30 $\%$ of all road traffic accidents in the country were accidents with pedestrians, $32 \%$ of all traffic fatalities were finished with pedestrian death.

Pedestrian crossing has the biggest risk level between all kinds of pedestrian facilities, because it includes a direct conflict point between vehicle and pedestrian traffics. The article presents a method to assess risk of pedestrian crossing users and to determine safety level of this road infrastructure element. This approach is based on observation and collection of infrastructural as well as traffic data, which includes: (1) information about each pedestrian crossing facility, its location and state, (2) data about accidents with pedestrians and their features, (3) data from road traffic measurements. The main advantages of the described method are universality and comprehensiveness.

The case study was done in Kristiine district of the city Tallinn, which was chosen as the most typical average district of Estonian capital. Results of this study are also presented in the article.

\section{INTRODUCTION}

Safety of pedestrians became a very important topic during the last years, especially, in the urban areas. Looking through official statistics, more than $40 \%$ of all accidents in Tallinn are accidents with pedestrian. It is clearly presented on the Figure 1: a number of collisions with pedestrians is more than total amount of accidents, where only vehicles participated. Figures 2 and 3 present distributions of accidents depending on years and on day time, respectively. According to the Figure 2, the most problematic situation was in the year 2012, where the largest amount of accidents was fixed. Distribution by day time shows two critical moments during 24 hours, when situation starts to be risky: these both moments align with traffic peak-hours in the morning (7-9 a.m.) and in the afternoon (16-18 p.m.).

To assess and to improve the situation, experince of neighbour countries must be taken into account primarily because of similar climate conditions and and behaviuors of road users. In case of Estonia the best examples could be provided by Finland and Sweden. 


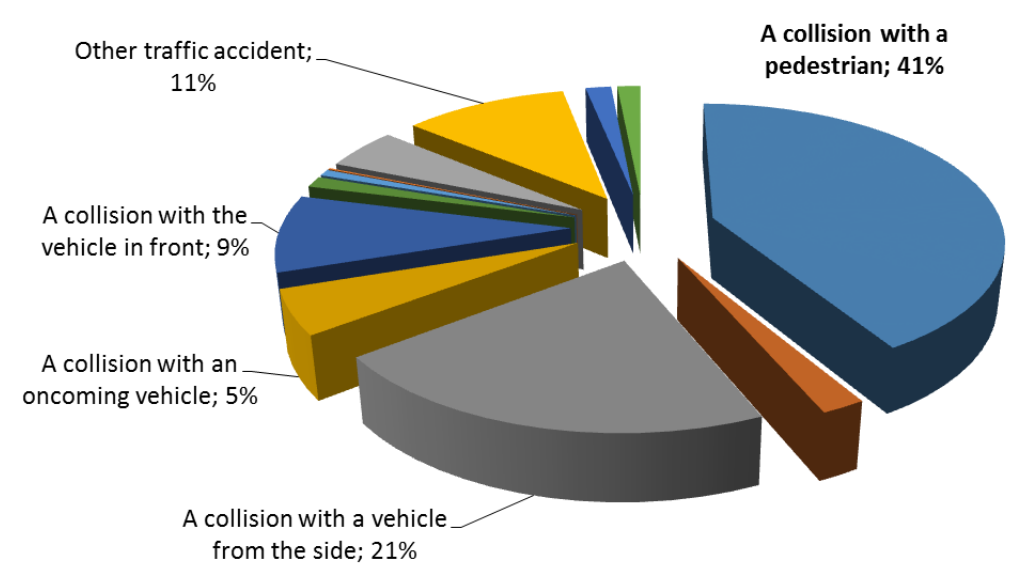

Fig. 1 - Fatal and injury accidents distribution by types

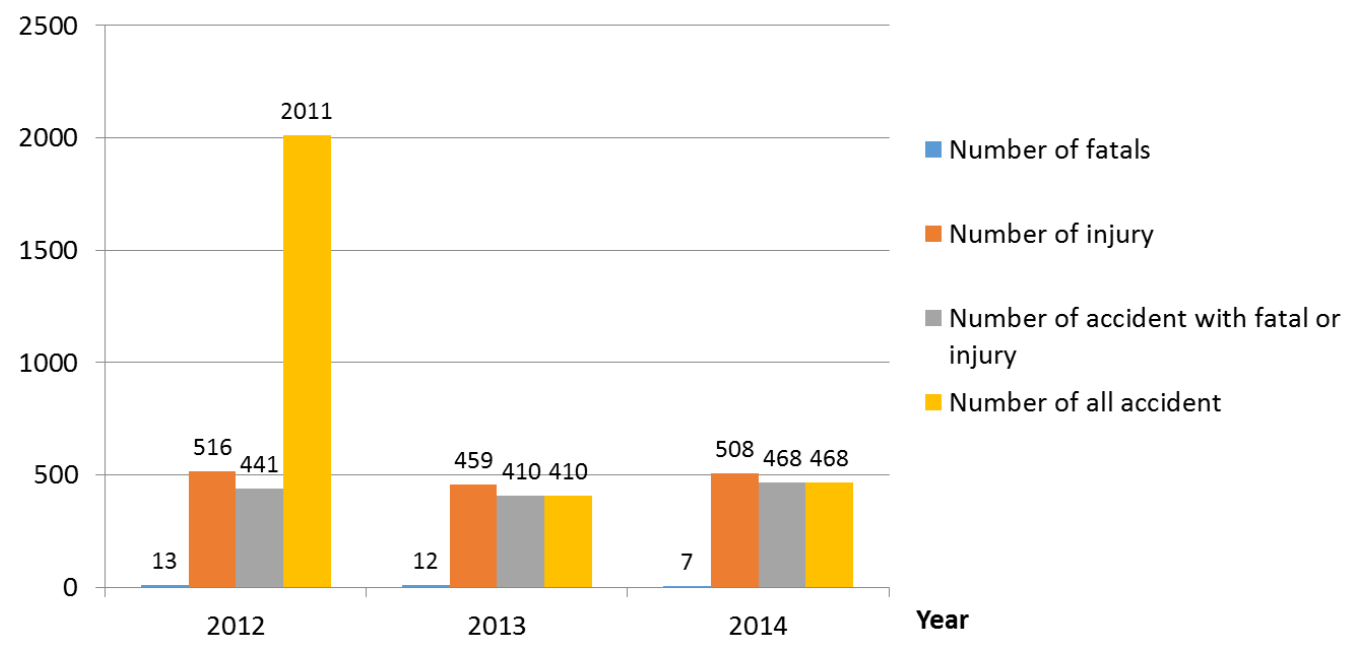

Fig. 2 - Number of accidents in Tallinn by years

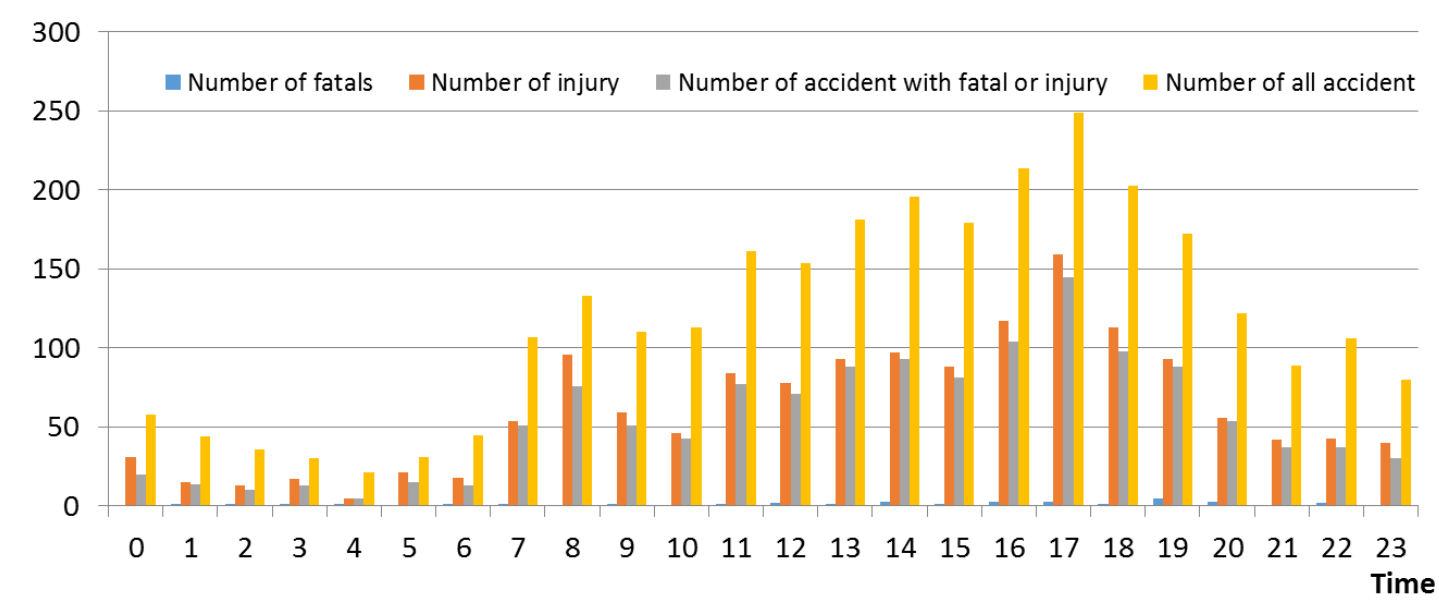

Fig. 3 - Number of accidents in Tallinn by time

Problem of experince transfer is studied during the last decades. View of Swedish research concerning pedestrian safety is shown in the article [3]. Comparison of road safety situations in Finland and Baltic States is presented in the research work [4]. Estonina basic issues in 
this topic are described in the article [5].

\section{METHODOLOGY}

Pedestrians refer to the most vulnerable road users. To prevent and to reduce accidents with thier participation was and will be one of the priority of road safety policy in Estonia. That is why risk assessment on pedestrian facilities could provided with perfect necessary feedbacks.

Table 1 - Potential risk factors included for pedestrian crossing risk assessment

\begin{tabular}{|c|c|c|c|}
\hline & Unsignalized pedestrian crossing & & Signalized pedestrian crossing \\
\hline \multicolumn{4}{|c|}{ I Type } \\
\hline 1 & Roadway width & 1 & Roadway width \\
\hline 2 & Number of driving lanes & 2 & Number of driving lanes \\
\hline 3 & Separating strip & 3 & Separating strip \\
\hline \multicolumn{4}{|c|}{ II Additional risk factors } \\
\hline 4 & Road edge with curb & 4 & Road edge with curb \\
\hline 5 & Cycleway along the roadway & 5 & Lighting \\
\hline 6 & Lighting & 6 & Alignment of crossing \\
\hline 7 & Alignment of crossing & 7 & $\begin{array}{l}\text { Children facilities located in the } \\
\text { neighborhood }\end{array}$ \\
\hline 8 & $\begin{array}{l}\text { Children facilities located in the } \\
\text { neighborhood }\end{array}$ & 8 & $\begin{array}{l}\text { Crossing covers bus stop pocket or turning } \\
\text { lane }\end{array}$ \\
\hline 9 & $\begin{array}{l}\text { Crossing covers bus stop pocket or turning } \\
\text { lane }\end{array}$ & 9 & Street signing quality \\
\hline 10 & $\begin{array}{l}\text { Distance to the nearest intersection and } \\
\text { the nearest signalized crossing }\end{array}$ & 10 & $\begin{array}{l}\text { Distance to the nearest intersection and the } \\
\text { nearest signalized crossing }\end{array}$ \\
\hline 11 & Road marking quality & 11 & Pedestrians cross the road nearby \\
\hline 12 & $\begin{array}{l}\text { Limited visibility due to traffic control } \\
\text { means }\end{array}$ & 12 & Traffic lights location and visibility \\
\hline 13 & Limited visibility due to parking & 13 & Other threats \\
\hline 14 & Pedestrians cross the road nearby & & \\
\hline 15 & Traffic signs location and visibility & & \\
\hline 16 & Other threats & & \\
\hline \multicolumn{4}{|c|}{ III: Safety measures introduced } \\
\hline 17 & Raised crossing or chicane & 14 & Single-stage crossing \\
\hline 18 & Road humps & 15 & Average waiting time \\
\hline 19 & Colored crossing & 16 & Crossing with push button \\
\hline 20 & Built safety island & 17 & Built safety island \\
\hline 21 & $\begin{array}{l}\text { Temporary safety island, introduced traffic } \\
\text { sign }\end{array}$ & 18 & $\begin{array}{l}\text { Temporary safety island, introduced traffic } \\
\text { sign }\end{array}$ \\
\hline 22 & Roadway narrowing at crossing & 19 & Roadway narrowing at crossing \\
\hline 23 & Local crossing lighting introduced & 20 & Local crossing lighting introduced \\
\hline 24 & $\begin{array}{l}\text { Precaution traffic sign or reflecting } \\
\text { background of traffic sign used }\end{array}$ & 21 & Displaying time \\
\hline 25 & Pedestrian guardrail & 22 & Pedestrian guardrail \\
\hline 26 & Other safety measures & 23 & Other safety measures \\
\hline \multicolumn{4}{|c|}{ IV: Speed } \\
\hline 27 & Real speed & 24 & Real speed \\
\hline \multicolumn{4}{|c|}{ V: Registered road accidents (injured or killed) } \\
\hline 28 & $\begin{array}{l}\text { Number of road accidents during the last } \\
36 \text { months }\end{array}$ & 25 & $\begin{array}{l}\text { Number of road accidents during the last } 36 \\
\text { months }\end{array}$ \\
\hline
\end{tabular}


Method for risk assessment at pedestrian crossings was chosen because of 2 reasons:

- Crossings are one of the main hazards to pedestrians

- Selected approach is quite comprehensive and covers different risk aspects.

This method divided all pedestrian crossing into two types: signalized and unsignalized. It based on 5 groups of risk:

1. General type of pedestrian crossings (width, lanes, separating strip)

2. Additional risk factors (deep description of road situation)

3. Existing safety measures

4. Speed

5. Road accident statistics

Detailed description of all risk aspects is in the Table 1. Depending on values of factors, each pedestrian crossing gets its assessment rate, which adds it to particular risk group: 1 - very high risk, 2 - high risk, 3 - average risk, 4 - low risk.

\section{KRISTIINE DISTRICT AS A STUDY AREA}

Tallinn is the capital of Estonia, which territory covers more than 150 sq.km and population is more than 440 thousands of inhabitants. It is divided into 8 administrative districts, which is shown on the Figure 4.

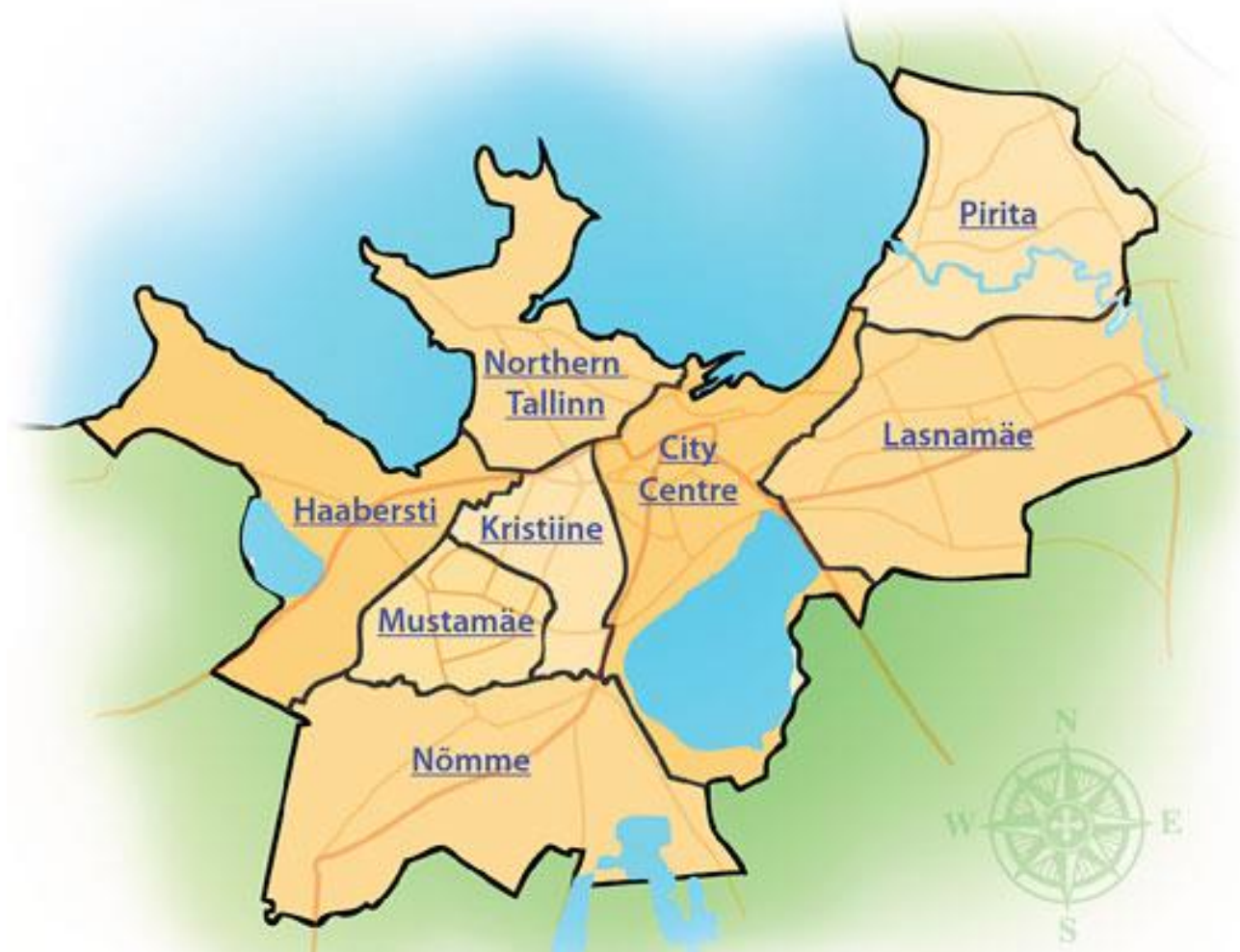

Fig. 4 - Administrative districts of Tallinn (source: https://www.tallinn.ee/eng/districts) 
Kristiine district was chosen as the most "average" district among existing ones in the perspective of population, area and location. Within the process of research work, information of about 180 pedestrian crossings located in this district was gathered. On the Figure 5 their positions were shown.

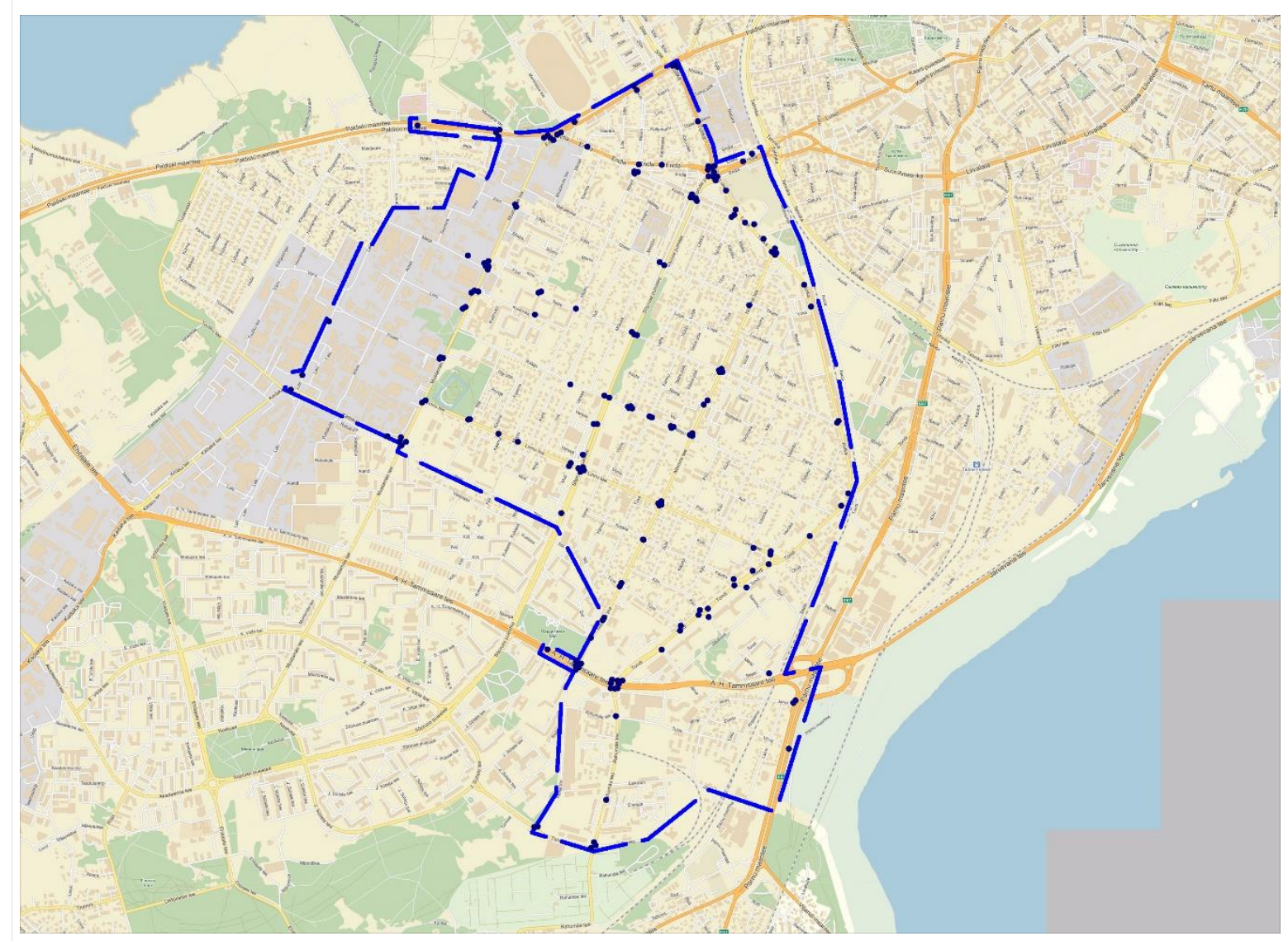

Fig. 5 - Location of all pedestrian crossings in the Kristiine district

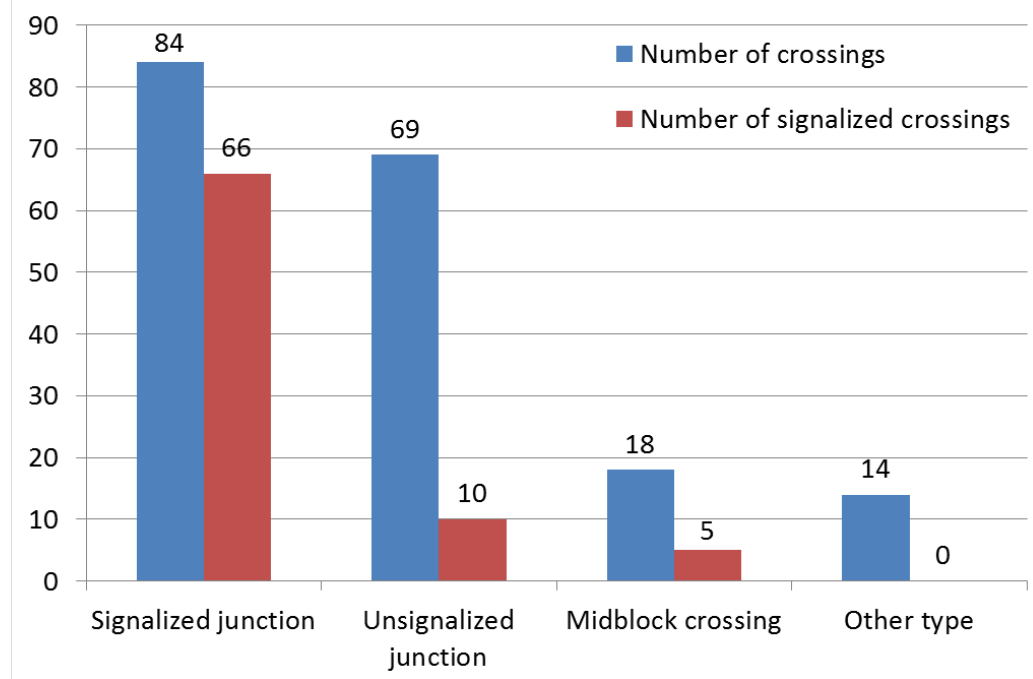

Fig. 6 - Number of crossings in the Kristiine districts by location types

Figure 6 presents the quantitative analysis of pedestrian crossing based on their type and 
location. As it is seen from this diagram, the main part of crossings in the research area are unsignalized and situated on the intersections. Figure 7 shows a topographic map with different type of pedestrian crossings: unsignalized ones are marked with blue color, signalized ones - with green color.

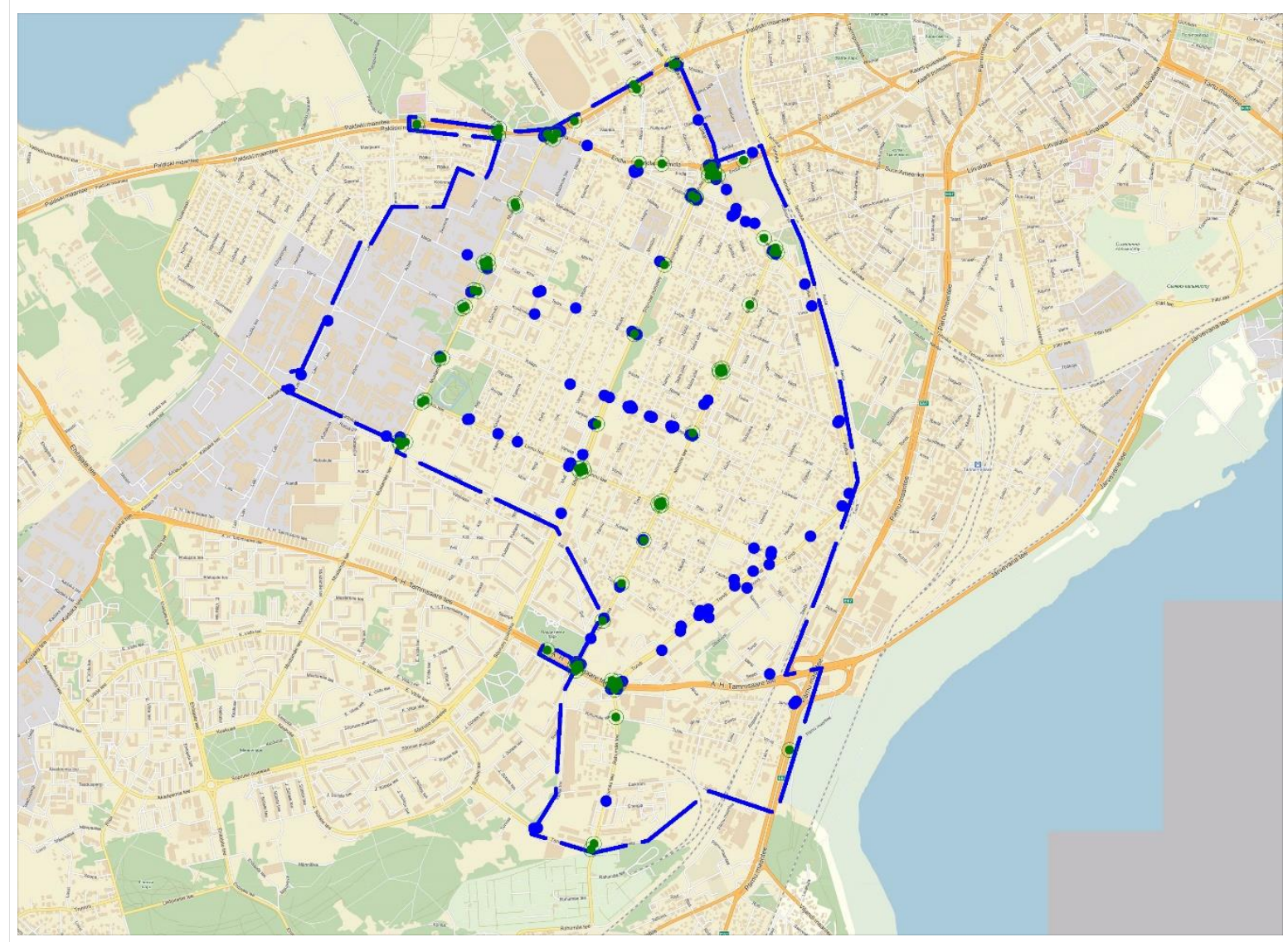

Fig. 7 - Location of signalized and unsignalized pedestrian crossings in the Kristiine district

As it was mentioned above, an amount of data about each selected facility was collected. This data presents mainly characteristics, which is necessary to know of risk calculation. Among them are location in WGS84 coordinate system, length of crossing, number of transport lanes, presence of central dividing strip or median islands, visibility of road users, visibility of road signs and traffic lights, availability of measures for improving pedestrian safety (such as additional lighting, road markings, humps, chicanes and other), etc.

\section{ANALYSIS OF STUDY RESULTS}

As it was mentioned above, the main aim of a case study was to carry out survey of pedestrian crossings in the Tallinn district and to assess their risks. This study was based on the above-described methodology and included collection and processing of data about regulatory documents and standards in the field of traffic organization, location of pedestrian crossings, its equipment and characteristics, analysis of transport infrastructure, estimation of traffic intensity in the Tallinn, estimation of accident rates on pedestrian crossings, 
calculation of risk rates based on various parameters of crossings. This work was done to get real results, which can help to detect potential "gaps" and problems on pedestrian crossings. Description of pedestrian crossing location was done above. To estimate accident rates, analysis of accident data was done. As a result, topographic map with different type of accident were created (Figure 8).

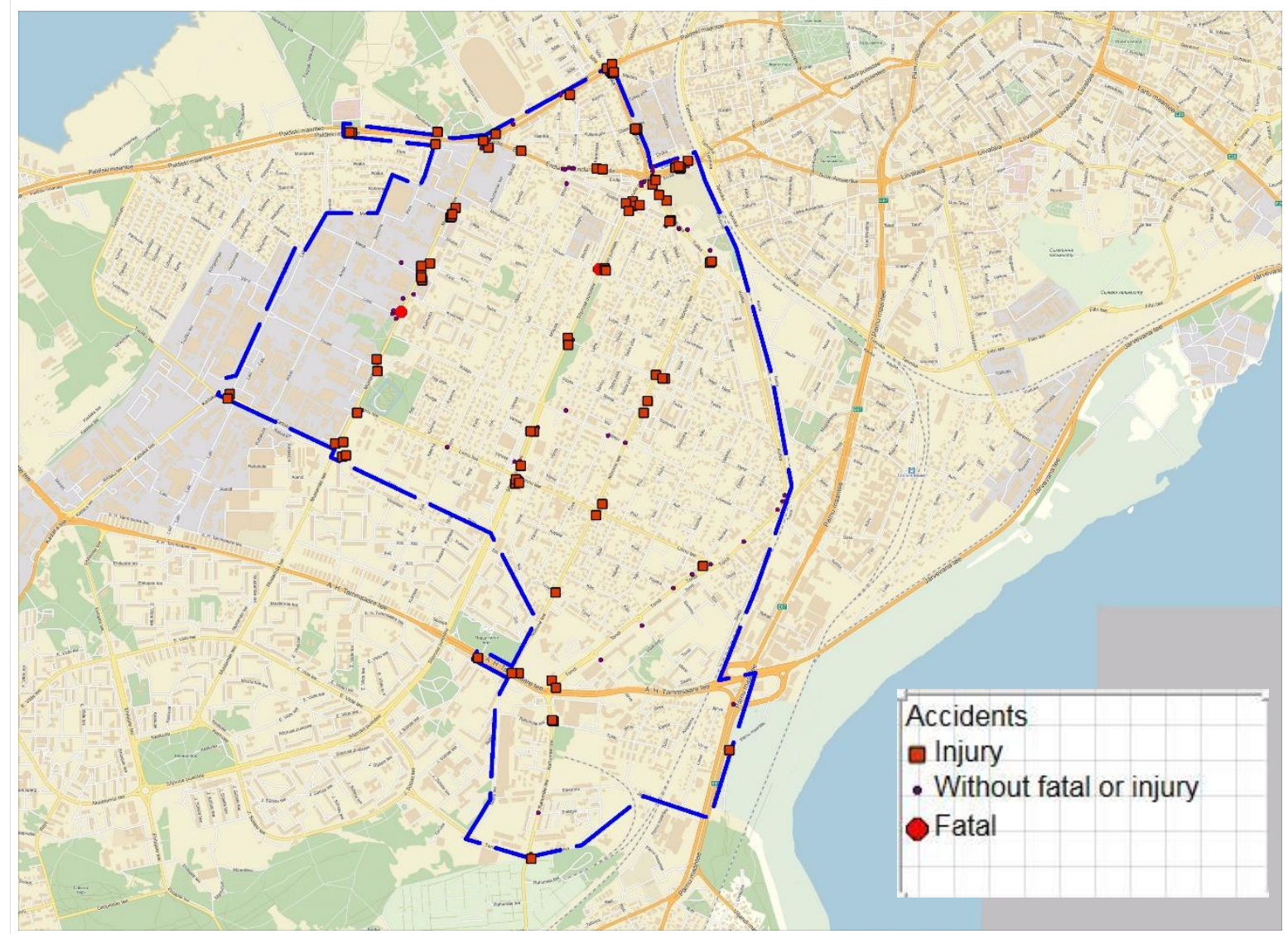

Fig. 8 - Accident rates on pedestrian crossing in the Kristiine district

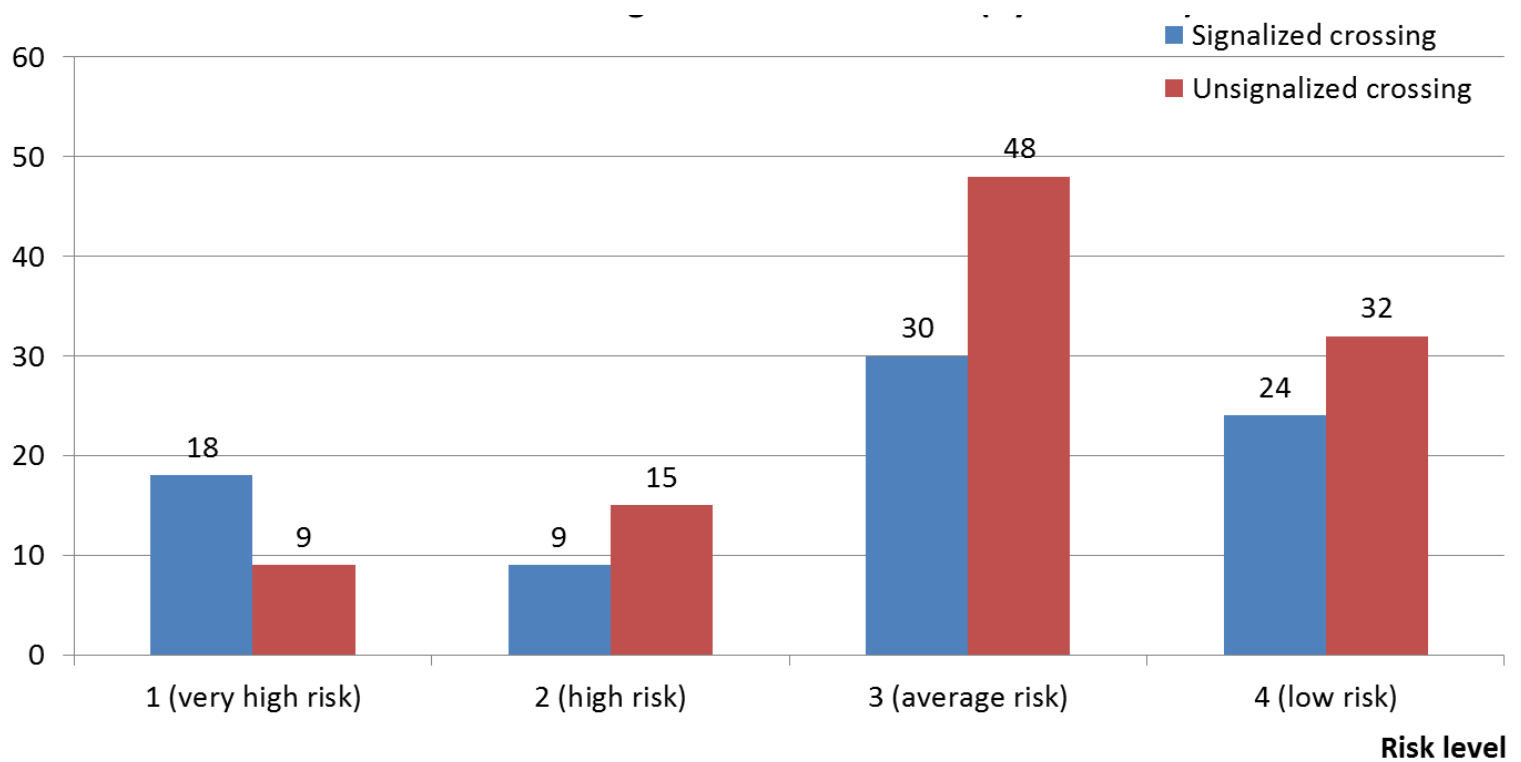

Fig. 9 - Risk levels of pedestrian crossing on Kristiine district 
Using all that data, the risk assessment of pedestrian crossings in the Kristiine district was done. Results of calculation are presented on the Figure 9 in form of risk levels/ safety level. They show quite high amount of pedestrian crossing with average risk level.

On the one hand, the method of risk assessment gives enough good results. On the other hand, such analysis revealed some difficulties in method application and there are possible ways for improving the calculation. For example, intensity of traffic and pedestrian flows is not involved in calculation, but it can have a great value in some cases.

\section{ACKNOLEDGEMENTS}

This research study and the participation in the Conference was supported by the ESF DoRa Programme Activity 5 "Facilitating international research cooperation by supporting shortterm research projects of visiting doctoral students in Estonia" and the Dora Plus Programme Action 1 "Participation of young researchers and Master's degree students in the international exchange of knowledge", respectively.

\section{REFERENCES}

[1] Antov, D.; Rõivas, T.; Pashkevich, M.; Ernits, E. (2014). Safety assessment of pedestrian crossings. In: Urban Street Design \& Planning, A. Pratelli (Ed.). Great Britain: WIT Press, Transport Systems and Traffic Engineering; 2, pp. 41-54.

[2] Antov, D.; Rõivas, T.; Antso, I.; Sürje, P. (2011). A method for pedestrian crossing risk assessment. In: Seventeenth International Conference on Urban Transport and the Environment: Urban Transport XVII, Pisa, Italy, 2010, Brebbia (Ed.). C. WIT Press, WIT Transactions on The Built Environment; 116, pp. 587-600.

[3] Hydén, C. (2010). The safety of pedestrians. In: the 23rd ICTCT Workshop in the Hague, Netherlands, 2010.

[4] Pihlak, I., Antov, D. (2002). Unterschiede in der Strassenverkehrssicherheit Zwischen den Baltischen Staaten und Finnland. Strassenverkehrstechnik, 8/2002. pp. $394-400$.

[5] Antov, D., Sööt, S. (2002) Toward Improved Traffic Safety: Road Use Perception and Behavior in Estonia. Journal of the Transportation Research Board. Transportation Research Record No 1818, Washington, D.C. pp. 1-6.

[6] Estonian National Road Safety Programme 2003-2015 (2003). The Estonian Road Administration. 